\title{
Do Internal Control Activities Adversely Influence the Profitability and Solvency of South African
} SMMEs?

\author{
Juan-Pierré Bruwer \\ Graduate Centre for Management, Cape Peninsula University of Technology, South Africa \\ BruwerJP@cput.ac.za
}

\begin{abstract}
Internal control activities should provide reasonable assurance surrounding the attainment of business objectives in the foreseeable future, be they financial or non-financial in nature. Recent studies suggest that internal control activities used within South African Small, Medium and Micro Enterprises (SMMEs) are inadequate and/or ineffective - they do not provide reasonable assurance surrounding the attainment of relevant objectives. For this study emphasis was placed on whether internal control activities used by South African SMMEs had an adverse influence on their profitability and solvency. Data were obtained from 119 members of management of South African SMMEs, which allowed a total of14 relationships to be tested. Only four relationships were found to be statistically significant which led to the rejection of the two developed hypotheses. Stemming from the results, it appears that there may be a need for the development of formal policies pertaining to internal control within a South African SMME dispensation.
\end{abstract}

Keywords: Solvency, profitability, South Africa, SMMEs, internal control

\section{Introduction}

Small, Medium and Micro Enterprises (SMMEs) play an important socio-economic role in both developed economies and developing economies around the globe, mainly by means of assisting with the distribution of wealth, the eradication of poverty and the decreasing of unemployment (Hill, 2001) (Wren \& Storey, 2002) (Chepurenko, 2010). In a South African dispensation these business entities are believed to add approximately $57 \%^{1}$ to the national Gross Domestic Product while providing employment opportunities to at least $61 \%$ of the national workforce (Naidoo \& Urban, 2010) (Swart, 2011) (Ngary, Smit, Bruwer, \& Ukpere, 2014). Albeit the socio-economic value which South African SMMEs add to the national economy, prior research (Fatoki \& Odeyemi, 2010)(Cant \& Wiid, 2013) (Moloi, 2013) suggests that 75\% of these business entities fail after being in existence for less than four years - a statistic believed to be among the worst in the world (Fatoki, 2014). This is concerning as an estimated $90 \%$ of all business entities which operate on South African soil can be classified as SMMEs (Mouloungui, 2012). According to previous studies (Van Eeden, Viviers, \& Venter, 2003)(Radas \& Božić, 2009)(SAICA, 2015) the failure rate of South African SMMEs is directly linked with their ability to manage economic factors ${ }^{2}$ and the risks associated with these factors.

One manner in which economic factors and their associated risks can be managed is through the implementation of a sound system of internal control. A system of internal control is a structured process that comprises five integral and inter-related elements which should assist in the mitigation of risks which, in turn, should provide reasonable assurance that relevant business objectives will be attained in the foreseeable future(COSO, 1992)(COSO, 2012). The five inter-related elements of a system of internal control pertain to (Coetzee, 2006) (Abu-Musa, 2009) (COSO, 2012) (McNally, 2013); (Martin, Sanders, \& Scalan, 2014): 1) control environment (the overall attitude of management towards internal control), 2) risk assessment (the identification and evaluation of risks), 3) internal control activities (the activities which prevent, detect and correct risks), 4) information and communication (the dissemination of information to allow relevant stakeholders to achieve their individual objectives to, in turn, help a business entity achieve its objectives), and 5) monitoring (ensuring that all elements in the system of internal control are adequate and effective). Although all of the five aforementioned inter-related elements are essential for a system of internal control to operate adequately and effectively, this study placed focus on the element of internal control activities within a South African SMME dispensation.

${ }^{1}$ This monetary value is estimated to be around US\$ 168.04 billion.

${ }^{2}$ Economic factors comprise of micro-economic factors (factors which can generally be reasonably controlled by management) and macro-economic factors (factors which are generally beyond the control of management). 
According to two previous local studies (Siwangaza, 2013)(Bruwer, 2016) it was found that South African SMMEs make use of inadequate and/or ineffective internal control activities which, in turn, do not provide reasonable assurance regarding the attainment of business objectives in the foreseeable future. This view is supported by a recent study (Bruwer \& Coetzee, 2017)which points out that implemented internal control activities in South African SMMEs do not provide reasonable assurance surrounding the financial sustainability $^{3}$ (the attainment of financial objectives) of these business entities. Taking into account the aforementioned, including the fact that no formal policies exist on internal control which should be evident in South African SMMEs, it becomes apparent that the implemented internal control activities in South African SMMEs do not necessarily add value to the overall sustainability of these entities at all; possibly also associated to their extensive failure rate.

In order for any business entity to remain in existence, it needs to be financially stable ${ }^{4}$ (Jeon, Amekudzi, \& Guensler, 2010). Otherwise stated, reasonable assurance should be provided that the business entity has more assets than liabilities (be solvent) which should result in the earning of more income compared to expenses incurred (be profitable). Thus, for this study focus is placed on whether implemented internal control in South African SMMEs adversely influenced these business entities' profitability and solvency. For the remainder of this paper relevant discussion takes place under the following headings: 1) theoretical discussion and hypothesis formulation, 2) research design, 3) results and discussion, 4) recommendations, and 5) conclusion.

\section{Literature Review}

Theoretical discussion and hypothesis formulation: Considering that this study makes use of multiple regression analyses (see Section 3), discussion takes place below to clarify the dependent variables (profitability and solvency) as well as the independent variable (internal control activities), after which the two formulated hypotheses for this study is stated.

Solvency and profitability: In order for most business entities to remain in operation in the foreseeable future a favourable financial position and a favourable financial performance are required ( (Jeon, Amekudzi, \& Guensler, 2010)(Lebacq, Baret, \& Stilmant, 2013). In layperson's terms the concept "financial position" pertains to the values of assets 5 , equity and liabilities ${ }^{6}$ while "financial performance" relates to the values of income and expenses (Beck, et al., 2016)(Flynn, et al., 2016). In order to measure the financial performance and financial position of a business entity, solvency and profitability are often used as yardsticks, respectively(Kiyosaki \& Lechter, 2003) (Kew \& Watson, 2012); (Bartlett, et al., 2014).Solvency has to do with the comparison between the size of assets and liabilities. If a business entity's assets are larger than its liabilities it is deemed to be solvent; if not, it is deemed as insolvent. In turn, profitability has to do with the comparison between the size of income and expenses. If a business entity's income is larger than its expenses, it is deemed to be profitable; if not it is deemed as non-profitable. In addition, the concepts of "solvency" and "profitability" are essentially intertwined with one another(Sowden-Service, 2006)in the sense that assets should generate income (e.g. sales, interest income, rent income, etc.) while liabilities normally result in expenditure (e.g. interest expense).

Internal control activities: Internal control activities are those activities which provide reasonable assurance, to management that relevant business objectives will be achieved in the foreseeable future by means of preventing, detecting and correcting risks which may have an adverse influence on these business objectives (McNally, 2013). Such activities can be automatic and/or manual in nature, as supported by formal policies and procedures, and are generally grouped into five categories(Frazer, 2012)(McNally, 2013) (Ejoh \&

\footnotetext{
${ }^{3}$ In the particular study, financial sustainability was conceptualized as the attainment of relevant financial objectives.

${ }^{4}$ Financial stability generally pertains to the phenomenon where a business' assets are larger than its liabilities (solvency) which, in turn, will allow for the same business to generate more income (stemming from assets) than incurring expenses (stemming from liabilities).

${ }^{5} \mathrm{An}$ asset is a resource which an entity controls, resulting from a past event, which will result in an inflow of economic benefits. These economic benefits should have a cost and/or value and a probability of an inflow.

${ }^{6} \mathrm{~A}$ liability is a present obligation of an entity, resulting from a past event, which will result in an outflow of economic benefits. These economic benefits should have a cost and/or value and a probability of an outflow.
} 
Ejom, 2014) (Halonen, 2014), namely: 1) document usage and design (relevant transactions and activities should be formally documented in a user-friendly manner to serve as an audit trail), 2) independent checks (objectively inspecting transactions and activities for inter alia accuracy, occurrence, validity and completeness), 3) safeguarding of assets (ensuring that both non-current assets and current assets are protected physically and/or virtually), 4) segregation of duties (the person that authorises transactions should be different to the person that records transactions; should be different to the person that executes transactions), and 5) proper authorisation activities (only members of management should be allowed to "green-light" transactions before they may take place).

Regardless of the type of internal control activities which are implemented in business entities, these activities need not only to function appropriately, but should also be adaptable to changes in applicable environments (e.g. economic environments, political environments and technological environments) to optimally mitigate risks (Agbejule \& Jokipii, 2009). By doing so, these activities will reasonably assure management that the relevant business entity will attain its objectives in the foreseeable future which, in turn, relate to the fulfilment of associated economic responsibilities, social responsibilities and/or environmental responsibilities (Rodgers, 2010) (Buys, 2012)(Bechtold, et al., 2013).In most cases, the manner in which economic responsibilities are fulfilled will ultimately determine whether a business entity will fail or not (Amendola, Giordano, Parrella, \& Restaino, 2017) (Small, Smidt, \& Joseph, 2017).Notwithstanding the above, in a South African SMME dispensation, two local studies (Siwangaza, 2013)(Bruwer, 2016)(Bruwer, Coetzee, \& Meiring, 2017) found that internal control activities are regarded as ineffective and/or inadequate as they do not provide reasonable assurance surrounding the attainment of relevant pre-determined business objectives in the foreseeable future. This view is further supported by (Bruwer \& Coetzee, 2017)who found that implemented internal control activities within these business entities do not provide any assistance toward the financial sustainability of these business entities. Thus, it becomes apparent that although internal control activities should allow members of management of these business entities reasonable assurance surrounding the attainment of their objectives in the foreseeable future, previous studies suggest the contrary.

Hypotheses developed and tested in this study: Using the above as a basis, especially taking into account previous studies surrounding the inadequate and/or ineffective internal control activities in South African SMMEs, the following two hypotheses were developed through placing emphasis on "what should happen" according to theory within the ambit of this study:

$\mathrm{H}_{1}$ : The internal control activities deployed by South African SMMEs have a statistically significant negative influence on this business entities' profitability.

$\mathrm{H}_{2}$ : The internal control activities deployed by South African SMMEs have a statistically significant negative influence on this business entities' profitability.

\section{Methodology}

The research design pertaining to this study is covered under the following three sub-headings below: 1) data and participants, 2) summary of valid demographical data, and 3) model specification.

Data and participants: This study was empirical in nature and fell in the positivistic research paradigm as it constituted quantitative research. Survey research was used whereby a questionnaire was disseminated to glean primary quantitative data from 119 South African SMME members of management (i.e. owners and/or managers). The questionnaire comprised mostly five point Likert-scale questions ( 1 = "strongly disagree", 2 = "disagree", 3 = "neither agree nor disagree", 4 = "agree", 5 = "strongly agree").

The targeted sample population was South African SMME members of management that had to adhere to a strict set of delineation criteria, namely: 1) they had to have decision making power in their SMMEs, 2) their SMMEs should have operated in the Fast Moving Consumer Goods industry ${ }^{7}$, 3) their SMMEs should have

${ }^{7}$ The Fast Moving Consumer Goods industry is characterized by high levels of competition and is based in the wholesale and retail industry (Bank, 2011). 
been regarded as either sole traders, partnerships, close corporations or private companies, 4) their SMMEs should have been regarded as a non-franchised business entity, 5) their SMMEs should have existed for at least 1 year, 6) their SMMEs should have employed less than 50 full-time employees, and 7) their SMMEs should have been based in the Cape Metropole, Western Cape, in South Africa. Non-probability sampling was used to target 150 South African SMME members of management, particularly a mixture of purposive sampling (see delineation criteria) and convenience sampling (the researcher was based in the Cape Metropole while the study was conducted).

Summary of valid demographical data: Out of the 150 targeted respondents, only 119 valid responses (79.33\%) were recorded as these respondents adhered to the strict set of delineation criteria. A summary of the valid demographical data, pertaining to the 119 respondents, is provided below:

- Position of respondents: $40.34 \%$ were owners; $32.77 \%$ were managers; $26.89 \%$ were ownermanagers.

- Managerial experience of respondents: $48.74 \%$ had less than 6 years' managerial experience; $51.26 \%$ had at least 6 years' managerial experience.

- Highest qualification of respondents: $18.49 \%$ had a partial secondary education; $48.74 \%$ had a secondary education; $32.77 \%$ had a tertiary education.

In addition, a summary of the valid demographical data, pertaining to respondents' SMMEs, is provided below:

- $\quad$ Type of SMMEs: $77.30 \%$ were sole traders; $9.2 \%$ were partnerships; $10.1 \%$ were close corporations; $3.4 \%$ were private companies.

- Operational methodologies of SMMEs: $80.67 \%$ operated on a "cash only" basis; $19.33 \%$ operated on a "cash and credit" basis.

- Description of SMMEs: $43.70 \%$ were retailers/wholesalers; $21.85 \%$ were restaurants/caterers; $31.93 \%$ were convenience stores/cafés; $2.52 \%$ were pharmacies.

- Employees employed by SMMEs: $87.40 \%$ employed 10 or less full-time employees; $12.6 \%$ employed between 11 and 50 full-time employees.

- Existence of SMMEs: $24.37 \%$ existed for less than four years (but at least one year); $75.63 \%$ existed for at least four years.

Moreover, when respondents were asked whether their respective SMMEs were perceived as profitable a mean score of 3.66 was calculated (translating to a response between "neither agree nor disagree" and "agree"). When respondents were asked whether their respective SMMEs were perceived as solvent a mean score of 3.45 was calculated (translating to a response between "neither agree nor disagree" and "agree"). A total of 43 items were used to measure both the independent variable (internal control activates) and the dependent variables (profitability and solvency), however only the number of items used to measure the independent variable were reduced through principle axis factoring ${ }^{8}$. Specifically, a total of 41 items were reduced to four factors and three items; as summarised per Table 1.

Table 1: Summary of reliability tests on items measuring internal control activities

\begin{tabular}{llll}
\hline Factor tested & Number of items & Cronbach's Alpha & KMO test score \\
\hline Document* & 11 & 0.867 & 0.853 \\
Safeguard* & 10 & 0.804 & 0.817 \\
Independent* & 14 & 0.839 & 0.793 \\
Authorisation & 3 & 0.380 & 0.574 \\
Segregation* & 3 & 0.829 & 0.718 \\
\hline
\end{tabular}

* Legitimate factor

Source: Researcher's own construct

8If the calculated Cronbach's Alpha value and KMO value of a factor is 0.600 or higher, such a factor is deemed as a legitimate factor(Field, 2009)(Cohen \& Sayag, 2010). 
Model specification: In this study, multiple regression models were developed to determine the relationships which exist between the implemented internal control activities in sampled South African SMMEs and their profitability and their solvency. The following models ${ }^{9}$ were used:

PROFIT $=\alpha+\beta_{1}$ DOCUMENT $+\beta_{2}$ SAFEGUARD $+\beta_{3}$ INDEPENDENT $+\beta_{4}$ SEGREGATION $+\beta_{5}$ AUTHORMAN + $\beta_{6}$ AUTHOREMPP $+\beta_{7}$ AUTHOREMPM $+\varepsilon$.

SOLVENT $=\alpha+\beta_{1}$ DOCUMENT $+\beta_{2}$ SAFEGUARD $+\beta_{3}$ INDEPENDENT $+\beta_{4}$ SEGREGATION $+\beta_{5}$ AUTHORMAN + $\beta_{6}$ AUTHOREMPP $+\beta_{7}$ AUTHOREMPM $+\varepsilon$.

All variables that were applied in the model above, including their measurements are described in Table 2 .

Table 2: Description and measurement of variables used in this study

\begin{tabular}{|c|c|c|}
\hline Variable & Description & Measurement \\
\hline \multicolumn{3}{|l|}{ Dependent } \\
\hline PROFIT & Profitability & $\begin{array}{l}\text { It measures the profitability of SMMEs. It assumes a } \\
\text { value between } 1 \text { and } 5 \text {, where } 1 \text { indicates "strongly } \\
\text { disagree" and } 5 \text { indicates "strongly agree". }\end{array}$ \\
\hline SOLVENT & Solvency & $\begin{array}{l}\text { It measures the solvency of SMMEs. It assumes a value } \\
\text { between } 1 \text { and } 5 \text {, where } 1 \text { indicates "strongly disagree" } \\
\text { and } 5 \text { indicates "strongly agree". }\end{array}$ \\
\hline \multicolumn{3}{|l|}{ Independent } \\
\hline DOCUMENT & $\begin{array}{l}\text { Adequate document usage } \\
\text { and design }\end{array}$ & $\begin{array}{l}\text { It shows whether documents used by SMMEs are } \\
\text { adequately used and designed. It assumes a value } \\
\text { between } 1 \text { and } 5 \text {, where } 1 \text { indicates "strongly disagree" } \\
\text { and } 5 \text { indicates "strongly agree". }\end{array}$ \\
\hline SAFEGUARD & Safeguarding of assets & $\begin{array}{l}\text { It shows whether assets are safeguarded in SMMEs. It } \\
\text { assumes a value between } 1 \text { and } 5 \text {, where } 1 \text { indicates } \\
\text { "strongly disagree" and } 5 \text { indicates "strongly agree". }\end{array}$ \\
\hline INDEPENDENT & Independent checks & $\begin{array}{l}\text { It shows whether independent checks are used by } \\
\text { SMMEs. It assumes a value between } 1 \text { and } 5 \text {, where } 1 \\
\text { indicates "strongly disagree" and } 5 \text { indicates "strongly } \\
\text { agree". }\end{array}$ \\
\hline SEGREGATION & Segregation of duties & $\begin{array}{l}\text { It shows whether duties are segregated in SMMEs. It } \\
\text { assumes a value between } 1 \text { and } 5 \text {, where } 1 \text { indicates } \\
\text { "strongly disagree" and } 5 \text { indicates "strongly agree". }\end{array}$ \\
\hline AUTHORMAN & $\begin{array}{l}\text { Only management can } \\
\text { authorise transactions }\end{array}$ & $\begin{array}{l}\text { It shows whether transactions are authorised only by } \\
\text { management. It assumes a value between } 1 \text { and } 5 \text {, where } \\
1 \text { indicates "strongly disagree" and } 5 \text { indicates "strongly } \\
\text { agree". }\end{array}$ \\
\hline AUTHOREMPP & $\begin{array}{l}\text { Employees can authorise } \\
\text { transactions based on } \\
\text { policies }\end{array}$ & $\begin{array}{l}\text { It shows whether transactions are authorised by } \\
\text { employees, as supported by policies. It assumes a value } \\
\text { between } 1 \text { and } 5 \text {, where } 1 \text { indicates "strongly disagree" } \\
\text { and } 5 \text { indicates "strongly agree". }\end{array}$ \\
\hline AUTHOREMPM & $\begin{array}{l}\text { Employees can authorise } \\
\text { transactions only with } \\
\text { management's permission }\end{array}$ & $\begin{array}{l}\text { It shows whether transactions are authorised by } \\
\text { employees only with the approval of management. It } \\
\text { assumes a value between } 1 \text { and } 5 \text {, where } 1 \text { indicates } \\
\text { "strongly disagree" and } 5 \text { indicates "strongly agree". }\end{array}$ \\
\hline
\end{tabular}

Source: Researcher's own construct

${ }^{9}$ The symbols " $\alpha$ " and " $\varepsilon$ " represent the constant(s) and error(s) in each model. 


\section{Results and Discussion}

Out of 14 tested relationships only four were found to be statistically significant- equivalent to $28.57 \%$ of all tested relationships. A summary of the results from the multiple regression analyses performed is shown in Table 3. Stemming from the results, the $\mathrm{R}^{2}$ was calculated at $12.70 \%$ for relationships pertaining to PROFIT and at $11.20 \%$ for relationships pertaining to SOLVENT. These $\mathrm{R}^{2}$ values can be interpreted as indications of very weak explanations of the variances which existed among relevant variables. Otherwise stated, out of the 14 tested relationships there were very few relationships that were statistically significant - justified by three that could be used to predict the dependent variable PROFIT and one that could be used to predict the dependent variable SOLVENT. Out of the four statistically significant relationships, two were positive (one at the $5 \%$ level and one at the $10 \%$ level) and two were negative (one at the $5 \%$ level and one at the $10 \%$ level). Three of the four statistically significant relationships pertained to PROFIT; the following statistically significant predictions could be made in relation to hypothesis $\mathrm{H}_{1}$ :

- At a 90\% confidence interval, if SAFEGUARD is used as internal control activity, it will result in a decrease in PROFIT of sampled South African SMMEs ( $\beta=-0.287)$.

- At a $90 \%$ confidence interval, INDEPENDENT are used as internal control activity, it will result in an increase in PROFIT of sampled South African SMMEs $(\beta=0.263)$.

- At a 95\% confidence interval, if SEGREGATION is used as internal control activity, it will result in an increase in PROFIT of sampled South African SMMEs ( $\beta=0.306)$.

Table 3: Summary of multiple regression analysis performed

\begin{tabular}{|c|c|c|c|}
\hline & & PROFIT & SOLVENT \\
\hline \multirow{3}{*}{$\begin{array}{l}\text { Independent } \\
\text { variables }\end{array}$} & $\mathrm{R}^{2}$ & 0.127 & 0.112 \\
\hline & $\mathrm{F}$ & 2.309 & 2.004 \\
\hline & Sig. & 0.031 & 0.061 \\
\hline \multirow{2}{*}{ DOCUMENT } & $\operatorname{Std} \beta$ & -0.131 & $-0.286^{* *}$ \\
\hline & Sig. & 0.343 & 0.041 \\
\hline \multirow{2}{*}{ SAFEGUARD } & $\operatorname{Std} \beta$ & $-0.287^{*}$ & -0.232 \\
\hline & Sig. & 0.074 & 0.151 \\
\hline \multirow{2}{*}{ INDEPENDENT } & $\operatorname{Std} \beta$ & $0.263^{*}$ & 0.149 \\
\hline & Sig. & 0.087 & 0.334 \\
\hline \multirow{2}{*}{ SEGREGATION } & $\operatorname{Std} \beta$ & $0.306^{* *}$ & 0.203 \\
\hline & Sig. & 0.017 & 0.114 \\
\hline \multirow{2}{*}{ AUTHORMAN } & $\operatorname{Std} \beta$ & 0.056 & 0.170 \\
\hline & Sig. & 0.598 & 0.112 \\
\hline \multirow{2}{*}{ AUTHOREMPP } & $\operatorname{Std} \beta$ & -0.079 & 0.048 \\
\hline & Sig. & 0.407 & 0.617 \\
\hline \multirow{2}{*}{ AUTHOREMPM } & $\operatorname{Std} \beta$ & -0.023 & 0.005 \\
\hline & Sig. & 0.817 & 0.958 \\
\hline \multicolumn{4}{|c|}{$\begin{array}{l}*=\text { Statistically significant at the } 10 \% \text { level } \\
* *=\text { Statistically significant at the } 5 \% \text { level }\end{array}$} \\
\hline
\end{tabular}

Source: Researcher's own construct

One of the four statistically significant relationships pertained to SOLVENT; the following statistically significant predictions could be made in relation to $\mathrm{H}_{2}$ :

- At a 95\% confidence interval, if DOCUMENT is used as internal control activity, it will result in a decrease in SOLVENT of sampled South African SMMEs $(\beta=-0.286)$. 
Although internal control activities should provide reasonable assurance to management that relevant business objectives will be achieved in the foreseeable future, it appears that one internal control activities had a negative statistically significant relationship with the PROFIT of sampled South African SMMEs; one had a negative statistically significant relationship with the SOLVENT of sampled South African SMMEs. In the same vein, two internal control activities were found to have a positive statistically significant relationship with the PROFIT of sampled South African SMMEs. Thus, since the bulk of internal control activities did not have a negative statistically significant relationship with the PROFIT and SOLVENT of sampled South African SMMEs, enough evidence was provided to reject both hypotheses $\mathrm{H}_{1}$ and $\mathrm{H}_{2}$. Below, discussion takes place surrounding the results pertaining to the PROFIT and SOLVENT of sampled South African SMMEs, respectively.

Discussion of results pertaining to PROFIT: In relation to SAFEGUARD, on the one hand it is highly probable that that these internal control activities were lax in sampled South African SMMEs as they were not necessarily working as indented. On the other hand, it may be possible that there was an overabundance of such internal control activities (e.g. key-card access panels at access points, sign-in books, safety gates and locked doors which require keys, etc.) which may have resulted in a decreased morale of stakeholders as it may be synonymous with a type of "danger zone"; impacting negatively on the PROFIT. Moreover, the maintenance of such excessive internal control activities may also have resulted in expenses of sampled South African SMMEs to increase. With independent being a relatively cheap type of internal control activity to implement, it may be the case that management of sampled South African SMMEs made proper use of this internal control activity to mitigate risks, especially in relation to having overstated expenses and/or understated income. Such initiatives may have included inter alia random cash counts, inventory counts and regular reconciliations (debtors, creditors and bank). Despite the fact that the bulk of sampled South African SMMEs employed 10 employees or less, it appears that those business entities which made use of SEGREGATION were better off in relation to PROFIT than those that did not make use thereof. It is highly probable that when SEGREGATION was evident, the risk of fraud (e.g. theft of inventory, misappropriation of cash, understatement of income, the overstatement of expenses, etc.) was minimised.

Discussion of results pertaining to SOLVENT: One of the four statistically significant relationships pertained to SOLVENT; the following statistically significant predictions could be made in relation to $\mathrm{H}_{2}$ :

- At a 95\% confidence interval, if DOCUMENT is used as internal control activity, it will result in a decrease in SOLVENT of sampled South African SMMEs $(\beta=-0.286)$.

In relation to DOCUMENT, members of management in sampled South African SMMEs may have made use of excessive paperwork when transactions were went on (e.g. procurement documentation, intent to purchase documentation, goods received note and pro forma invoice, quality check document, good received note, duplicate delivery note, confirmation of receipt etc.). When there is an overkill approach with any internal control activity may result in decreased productivity and/or reduced focus of employees (being overwhelmed). Alternatively, it may be the case that relevant DOCUMENT was just badly designed which may have led to employees committing irregularities (e.g. collusion, theft, white collar crime, etc.) which, in turn, could have adversely influence the size of assets (goods).

Recommendations: In any business entity, the responsibility of implementing adequate and effective internal control activities rest with management. From the study conducted, it is clearly evident that the implemented internal control activities in sampled South African SMMEs are not adequate and/or effective as they do not contribute to the PROFIT of these business entities; minimally to their SOLVENT. As such, it is strongly recommended that members of management of sampled South African SMMEs re-evaluate their implemented internal control activities and ascertain: 1) whether it is needed, 2) whether is enough, 3) whether it is working as intended, and 4) whether it helps with the provision of reasonable assurance surrounding relevant business objectives. It is also recommended that national government draws up a green paper with the intent to spur on discussion between applicable stakeholders to enhance the (financial and/or non-financial) sustainability of South African SMMEs. This green paper should pertain to, inter alia, formal guidance documentation (user-friendly) for South African SMMEs to enhance their overall sustainability (e.g. 
free step-by-step guidebooks, information on free skill development programmes) while simultaneously also giving members of management of these business entities incentives for contributing to the achievement of socio-economic objectives (e.g. employing $\mathrm{x}$-amount of people, distributing $\mathrm{x}$-amount of profits in the form of donations, etc.).

\section{Conclusion}

According to scholarly literature, internal control activities should provide reasonable assurance surrounding the attainment of a business entity's objectives in the foreseeable future. When taking into account the results from the study out of the 14 tested relationships, only four were statistically significant -three related to the PROFIT (one negative and two positive) and one related to the SOLVENT (negative) of sampled South African SMMEs - the inference was made that implemented internal control activities in sampled South African SMMEs are not necessarily adequate and/or effective. This sentiment is further supported by the fact that ten tested relationships $(71.43 \%$ ) were not statistically significant in relation to both the PROFIT and SOLVENT of sampled South African SMMEs. Thus, both $\mathrm{H}_{1}$ and $\mathrm{H}_{2}$ were rejected. It may be the case that implemented internal control activities, were not meticulously evaluated before being implemented and/or that these activities were not periodically monitored by management to ascertain (and evaluate) their adequacy and/or effectiveness. In conclusion, the results from this study reaffirm the findings made by previous studies that South African SMMEs make use of inadequate and/or ineffective internal control activities as they do not all provide reasonable assurance surrounding the attainment of these business entities' financial objectives, at least, in the foreseeable future.

\section{References}

Abu-Musa, A. (2009). Exploiting the importance and implementation of COBIT processes in Saudi organizations: an empirical study. Information Management and Computer Security, 17(2), 73-95.

Agbejule, A. \& Jokipii, A. (2009). Strategy, control activities, monitoring and effectiveness. Managerial Auditing Journal, 24(6), 500-522.

Amendola, A., Giordano, F., Parrella, M. \& Restaino, M. (2017). Variable selection in high-dimentional regression: a nonparametric procedure for business failure preduction. Applied Stochastic Models in Business and Industry, 33(4), 355-368.

Bank, S. A. (2011). Standard industrial classification of all economic activities. Retrieved from https://www.resbank.co.za/Publications/Guides/Documents/Appendix\%20B\%20\%20Standard\%20industrial\%20classification\%20of\%20all\%20economic\%20activities.pdf

Bartlett, G., Beech, G., De Hart, F., De Jager, P., De Lange, J. \& Erasmus, P. (2014). Financial Management. Cape Town: Oxford University Press Southern Africa.

Bechtold, J., Kaspereit, T., Kirsch, N., Lyakina, Y., Seib, S. \& Spiekermann, S. \&. (2013). Corporate sustainability in the estimation of financial distress likelihood - Evidence from the world stock markets during the financial crisis. Research Journal of Finance and Accounting, 4(5), 205-211.

Beck, T., Bruwer, J. P., Beck, R., Chalmers, M., Maseko, J. \& Pele, P. \&. (2016). Applied Accounting. Cape Town: Oxford University Press Southern Africa.

Bruwer, J. (2016). The relationship(s) between the managerial conduct and the internal control activities of South African fast moving consumer goods Small, Medium and Micro Enterprises. Cape Peninsula University of Technology. Unpublished Manuscript (thesis).

Bruwer, J. \& Coetzee, C. (2017). Do independent checks positively influence the perceived financial sustainability of South African SMMEs? International Southern African Accounting Association Conference, (pp. 30-43). Durban.

Bruwer, J., Coetzee, P. \& Meiring, J. (2017). Can internal control activities and managerial conduct influence business sustainability? Journal of Small Business Enterprise Development, 24(3), 1-20.

Buys, J. (2012). A conceptual framework for determining sustainability of SMMEs in Lesedi.North West University. Unpublished Manuscript (dissertation).

Cant, M. \& Wiid, J. (2013). Establishing the challenges affecting South African SMEs. International Business and Economics Research Journal, 12(6).

Chepurenko, A. (2010). Small entrepreneurship and entrepreneurial activity of population in Russia in the context of the economic transformation. Historical Social Research, 301-319. 
Coetzee, P. (2006). Effect of HIV/AIDS on the control environment. Perspectives in Public Health, 183-190.

Cohen, A. \& Sayag, G. (2010). The effectiveness of internal auditing: An empirical examination of its determinants in Israeli Organizations. Australian Accounting Review, 20(3), 296-307.

COSO. (1992). Internal control - integrated framework, Committee of Sponsoring Organizations of the Treadway Commission. Jersey.

COSO. (2012). Internal control - integrated framework. Retrieved from http://www.ey.com/Publication/vwLUAssets/COSO_InternalControlFramework_September2012/\$ FILE/COSO_InternalControlFramework_September2012.pdf

Ejoh, N. \& Ejom, P. (2014). The impact of internal control activities on financial performance of tertiary institutions in Nigeria. Journal of Economics and Sustainable Development, 5(16), 133-143.

Fatoki, O. (2014). Enhancing access of external finance for new micro enterprises in South Africa. Journal of Economics, 2, 1-6.

Fatoki, O. \& Odeyemi, A. (2010). Which new small and medium enterprises in South Africa have access to bank credit? International Journal of Business and Management, 5(10), 128-136.

Field, A. (2009). Discovering statistics using SPSS. London: Sage Publications Ltd.

Flynn, D., Koornhof, C., Kleynhans, J., Meyer, L., Posthumus, L., Arendse, R. \& Muriro, R. (2016). Fundamental Accounting. Cape Town: Juta.

Frazer, L. (2012). The effect of internal control on the operating activities of small restaurants. Journal of Business and Economics Research, 10(6), 361-373.

Halonen, P. (2014). Risk-based evaluation of internal controls in case company's sales process - case company X. Aalto University. Unpublished Manuscript (thesis).

Hill, H. (2001). Small and medium enterprises in Indonesia: old policy challenges for a new administration. Asian Survey, 41(2), 248-270.

Jeon, C., Amekudzi, A. \& Guensler, R. (2010). Evaluating plan alternatives for transportation system sustainability: Atlanta metropolitan region. International Journla of Sustainable Transportation, 4(4), 227-247.

Kew, J. \& Watson, A. (2012). Financial Accounting: An Introduction. Cape Town: Oxford University Press Southern Africa.

Kiyosaki, R. \& Lechter, S. (2003). The Cashflow Quadrant. New York: Grand Central Publishing.

Lebacq, T., Baret, P. \& Stilmant, D. (2013). Sustainability indicators for livestock farming: a review. Agronomy for Sustainable Development, 33(2), 311-327.

Martin, K., Sanders, E. \& Scalan, G. (2014). The potential impact of COSO internal control integrated framework revision on internal audit structured SOX work programs. Research in Accounting Regulation, 3, 110-117.

McNally, J. (2013). The 2013 COSO framework and SOX compliance: one approach to an effective transition. Retrieved from http://www.coso.org/documents/COSO\%20McNallyTransition\%20ArticleFinal\%20COSO\%20Versi on\%20Proof_5-31-13.pdf

Moloi, N. (2013). The sustainability of construction small-medium enterprises (SMEs) in South Africa. Witwatersrand. Unpublished Manuscript (dissertation).

Mouloungui, S. (2012). Assessing the impact of finance on small business development in Africa: the cases of South Africa and Gabon. Tswane University of Technology. Unpublished Manuscript (dissertation).

Naidoo, R. \& Urban, B. (2010). The relevance of operational skills towards business sustainability: a focus on SMME manufacturers in the Vaal Triangle region. Acta Commercii, 10(1), 234-248.

Ngary, C., Smit, Y., Bruwer, J. P. \& Ukpere, W. (2014). Financial performance measures and business objectives attainment in fast food SMMEs in the Cape metropolis: a preliminary liability and suitability analysis. Mediterranean Journal of Social Science, 5(20), 909-921.

Radas, S. \& Božić, L. (2009). The antecedents of SME innovativeness in an emerging transition economy. Technovation, 29(6), 438-450.

Rodgers, C. (2010). Sustainable entrepreneurship in SMEs: a case study analysis. Corporate Social Responsibility and Environmental Management, 17(3), 125-132.

SAICA. (2015). 2015 SME insights report. Retrieved from http://www.saica.co.za/Portals/0/documents/SAICA_SME.PDF

Siwangaza, L. (2013). The status of internal controls in fast moving consumer goods SMMEs in the Cape Peninsula. Cape Peninsula University of Technology. Unpublished Manuscript (thesis). 
Small, R., Smidt, L. \& Joseph, A. (2017, March). Financial statements and the failure of SMEs. Professional Accountant (SAIPA), 3, 17-19.

Sowden-Service, C. (2006). Gripping GAAP. Durban: CSS Publishers.

Swart, M. (2011). Small businesses are set to lead economic recovery. Professional Accountant (SAIPA), 2, 1012.

Van Eeden, S., Viviers, S. \& Venter, D. (2003). A comparative study of selected problems encountered by small businesses in the Nelson Mandela, Cape Town and Egoli metropoles. Managment Dynamics, 12(3), 13-23.

Wren, C. \& Storey, D. (2002). Evaluating the effect of soft business support upon small firm performance. Oxford Economic Papers, 54(2), 334-365. 